\title{
O ensino religioso no Estado Laico Brasileiro e a Lei Municipal 7.280/2019
}

\author{
Lusival Antonio Barcellos* \\ Maria José Torres Holmes** \\ Marlene Pereira Borba Cahú*** \\ Ana Paula Rodrigues Cavalcanti****
}

\section{Resumo}

Este artigo versa sobre o Ensino Religioso (ER) e o Estado Laico Brasileiro. Com a aprovação da BNCC, em 2017, a instituição do ProBNCC e das Diretrizes Curriculares Nacionais em Ciências da Religião (DCNCR), em 2018, o ER passou a ser destaque no cenário nacional. Partindo da análise da Lei no 7.280/2019 e as interconexões naquele contexto, o estudo embasado na legislação vigente sobre o ER vai alicerçando os fundamentos legais deste componente curricular e mostrando uma trajetória histórica de conquistas que são superadas com a articulação e mobilização de vários profissionais. Autores como Freitas (2018), demonstram que os resultados do ER estão acontecendo numa escala ascendente, com possibilidades eminentes de implementação em todos os municípios e estados brasileiros.

Palavras-chave: Educação. Ensino Religioso. Formação. Laicidade. Legislação.

* Universidade Federal da Paraíba. Prof. do Depatamento e do Programa de Pós-Graduação em Ciências das Religiões, da Universidade Federal da Paraíba. lusivalb@gmail.com .

** Professora Aposentada da Rede Pública de Ensino. Licenciada em Pedagogia (Orientação Educacional). Doutoranda em Ciências das Religiões pela Universidade Federal da Paraíba. Grupo de Pesquisa FIDELID/UFPB. Membro/FONAPER. mjtholmes@yahoo.com.br .

*** Mestranda em Ciências das Religiões pela Universidade Federal da Paraíba. Graduada em Direito, Especialização Lato Sensu em Direito Civil e Processo Civil (UGF). Professora do Curso de Direito da UNIESP Centro Universitário, João Pessoa-PB. marlene.cahu@hotmail.com .

**** Universidade Federal da Paraíba (UFPB). Graduada em Nutrição. Doutora em Psicologia Social (UFPB). Professora do Programa de Pós-Graduação e do Departamento de Ciências das Religiões, da Universidade Federal da Paraíba. anapaulacavalcanti.ufpb@gmail.com . 


\title{
Religious studies in the Secular State in Brazil and Municipal Law 7.280/2019
}

\begin{abstract}
This article treats the Religious Studies (RE) and the Secular State in Brazil. With the approval of BNCC, in 2017, the institution of ProBNCC and the National Curricular Guidelines in Religious Studies (DCNCR), in 2018, RE became a highlight on the national scene. Based on the analysis of Law No. 7,280 / 2019 and the internal connections in that context, the study supported by the current legislation on RE is creating bases on the legal foundations of this curricular component and showing a historical trajectory of conquests that are overcome with articulation and mobilization of many professionals. Authors such as Freitas (2018), demonstrate that the results of the RE are happening on an upward scale, with eminent possibilities for implementation in all Brazilian municipalities and states.
\end{abstract}

Key words: Education. Religious Education. Formation. Secularity. Legislation.

\section{La educación religiosa en el Estado Laico Brasileño y la Ley Municipal 7.280/2019}

\section{Resumen}

Este artículo trata de la Educación Religiosa (ER) y el Estado laico brasileño. Con la aprobación de la BNCC, en 2017, la institución del ProBNCC y de las Directrices Curriculares Nacionales en Ciencias de las Religiones (DCNCR), en 2018, la ER se ha convertido en un punto culminante en el escenario nacional. Basado en el análisis de la Ley N. 7.280/2019 y las interconexiones en ese contexto, el estudio apoyado por la legislación actual sobre la ER va creando bases sobre los fundamentos legales de este componente curricular y demostrando una trayectoria historia de conquistas obtenidas con la articulación y movilización de muchos profesionales. Autores como Freitas (2018), demuestran que los resultados de la ER están sucediendo en una escala ascendente, con posibilidades eminentes de implementación en todos los municipios y estados brasileños. Palabras clave: Educación. Educación Religiosa. Formación. Secularidad. Legislación

\section{Introdução}

O presente artigo, faz uma análise da Lei n. 7.280 de 17 de julho de 2019, aprovada pela Câmara de Vereadores de Campina Grande - PB, sancionada pelo Prefeito constitucional da referida cidade, em 02 de setembro do mesmo ano, sob a ótica constitucional e das legislações para o Ensino Religioso (ER). O texto normativo já em seu destaque propõe a leitura bíblica nas escolas públicas e privadas daquele município. Por entender necessário, transcrevemos a seguir, na íntegra, a norma em comento:

A Lei no 7.280 de 17 de julho de 2019: Propõe a leitura bíblica nas escolas públicas e privadas do município de Campina Grande e dá outras providências. 
O PREFEITO MUNICIPAL DE CAMPINA GRANDE-PB. Faço saber que a Câmara de Vereadores aprovou e eu sanciono a seguinte, LEI:

Art. $1^{\circ}$ - Fica denominada a "Leitura da Bíblia" nas escolas públicas e privadas do Município de Campina Grande, onde visa trazer o conhecimento cultural, geográfico e científico, fatos históricos bíblicos.

Art. $2^{\circ}$ - O Poder Executivo regulamentará a presente Lei, no que couber, no prazo de 60 dias (sessenta dias), contados da sua publicação.

Art. $3^{\circ}-$ Esta lei entra em vigor na data de sua publicação.

Art. $4^{\circ}$ - Revogam-se as disposições em contrário. (CÂMARA MUNICIPAL DE CAMPINA GRANDE, 2019).

Percebe-se que a norma acima é por demais sucinta. Num primeiro momento, pode colocar o leitor menos atento a não perceber a profundidade e complexidade que demanda sua efetiva aplicação. O título ou caput se inicia com o verbo propor, no presente do indicativo, "propõe a leitura bíblica". "Propor" também pode significar sugerir, aconselhar indicar, recomendar, dentre outros sinônimos que se encontram com facilidade em qualquer dicionário da língua portuguesa.

Então, partimos do indicativo de que o Legislador Municipal pretende não obrigar, mas de fato, propor, recomendar ou sugerir a leitura bíblica às escolas das redes pública e privada. "Mais adiante, no seu artigo primeiro, o legislador optou por justificar o que denominou de "Leitura da Bíblia", asseverando que: "[...] visa trazer o conhecimento cultural, geográfico e científico, fatos históricos bíblicos". (CÂMARA MUNICIPAL DE CAMPINA GRANDE, 2019).

Passemos a análise do texto sob a ótica Constitucional. A Carta Magna de 1988, também chamada de Constituição Cidadã, no Título II, que trata ao longo do seu texto, dos Direitos e Garantias Fundamentais. O Capítulo I, mais particularmente, dispõe sobre os Direitos e Deveres Individuais e Coletivos. É importante ressaltar que este segundo, é espécie do gênero daquele primeiro, que tomamos como Direitos e Garantias.

Tal observação é deveras importante, pois, existem no texto consolidado, disposições meramente declaratórias, que tem o caráter de reconhecimento da existência positivada de direitos, como bens e vantagens e, disposições assecuratórias, garantidoras do direito, defendendo-o, são instrumentos preventivos que asseguram o exercício ou mesmo sua reparação, no caso de ser violada, temática enfrentada por Rui Barbosa (apud LENZA, 2020). Não é incomum que num mesmo dispositivo seja ao mesmo tempo assecuratórios e garantidoras, como é o caso do inciso VI, do artigo $5^{\circ}$, senão vejamos: 
Art. $5^{\circ}$ - Todos são iguais perante a lei, sem distinção de qualquer natureza, garantindo-se aos brasileiros e aos estrangeiros residentes no País a inviolabilidade do direito à vida, à liberdade, à igualdade, à segurança e à propriedade, nos termos seguintes: [...]

VI- É inviolável a liberdade de consciência e de crença, sendo assegurado o livre exercício dos cultos religiosos e garantida, na forma da lei, a proteção aos locais de culto e suas liturgias. (BRASIL, 2020a).

Apesar de fazermos referência a atual Constituição de 1988, é certo que, desde o advento da República, Decreto n ${ }^{\circ} 119-\mathrm{A}^{1}$, de 17 de janeiro de 1890 (site Planalto), existe, ao menos legalmente, a separação entre Estado e a Igreja, portanto, inexiste religião oficial no Brasil, que é país laico ou não confessional e leigo. Portando é poder e dever do Estado, tanto no âmbito Federal, Estadual e Municipal, colocar-se de forma neutra perante as religiões e cultos religiosos praticados em todo território nacional.

A laicidade não se apresenta no texto constitucional como uma ferramenta facultativa, ou mesmo deixa margens a interpretações hermenêuticas (CECCHETTI, 2016). Ao contrário, ao passo que a primeira parte do inciso VI do artigo $5^{\circ}$, tem conteúdo declaratório "É inviolável a liberdade de consciência e de crença, sendo assegurado o livre exercício dos cultos religiosos [...]”. No seu segundo momento é garantidor "[...] e garantida, na forma da lei, a proteção aos locais de culto e suas liturgias.” (BRASIL, 2020a).

As liberdades são públicas porque são protegidas e reconhecidas pelo Estado, devendo o mesmo ser seu garantidor. É imprescindível que o cidadão possa escolher por si mesmo sua conduta, dentro dos limites legais. Tal liberdade está diretamente ligada à educação como direito de todos e dever do Estado.

Os poderes públicos, assim como os particulares estão vinculados aos direitos fundamentais apesar da ausência de dispositivo expresso, nesse sentido. Tal se justifica pelo fato de que, em nosso direito constitucional, o postulado da aplicabilidade imediata das normas de direitos fundamentais (art. $5^{\circ}, \int 1^{\circ}$, da $\mathrm{CF}$ ) pode ser compreendido como um mandado de otimização de sua eficácia, pelo menos no sentido de impor aos poderes públicos a aplicação imediata dos direitos fundamentais, outorgando-lhes, nos termos desta aplicabilidade, a maior eficácia possível (SARLET, 2018). Portanto,

1 Art. $1^{\circ}$ É proibido a autoridade federal, assim como á dos Estados federados, expedir leis, regulamentos, ou atos administrativos, estabelecendo alguma religião, ou vedando-a, e criar diferenças entre os habitantes do país, ou nos serviços sustentados á custa do orçamento, por motivo de crenças, ou opiniões filosóficas ou religiosas. 
todo ato do poder público está subjugado a Carta Máxima e, uma inequívoca proibição a leis contrárias aos direitos fundamentais (SANTOS, 2019).

A vinculação aos direitos fundamentais significa uma delimitação material de liberdade para o legislador, no âmbito de sua atividade regulamentadora, dever de conformação de acordo com o padrão estabelecido pelas normas de direitos fundamentais, do qual a Lei $n^{\circ} 7.280$ de 17 de julho de 2019 do Município de Campina Grande, que dispõe sobre "Leitura da Bíblia" não se desincumbiu.

\section{Como fica a laicidade do estado brasileiro?}

A casa Legislativa Municipal de Campina Grande, apesar de não ter optado por uma norma de natureza impositiva, direcionou a recomendação da "Leitura da Bíblica", nas escolas particulares e públicas, livro religioso próprio do Cristianismo, indicativo direcionamento religioso. Não bastasse tal propositura, achou por bem de justificar, que tal prática "[...] visa trazer o conhecimento cultural, geográfico e científico, fatos históricos bíblicos.” (CÂMARA MUNICIPAL DE CAMPINA GRANDE, 2019).

Embora o Estado Brasileiro seja laico, a própria Constituição em seu preâmbulo $^{2}$, invoca a proteção de Deus. Admite ainda, em seu art. 210 , J $1^{\circ}$, que sob forma de disciplina de matrícula facultativa, o Ensino Religioso nas escolas públicas do ensino fundamental é obrigatório a ser ofertado. Outrossim, prestigia o direito de que cada cidadão nacional pratique e vivencie a sua fé, sem imposição Estatal, ou seja, protege em grau máximo a liberdade religiosa (SANTOS, 2019).

Para Mendes (2017, p. 219), “[...] o reconhecimento da liberdade religiosa decerto que contribui para prevenir tensões sociais, na medida em que, por ela, o plural e se instala e se neutralizam rancores e desavenças decorrentes do veto oficial a crenças quaisquer."

O Tribunal Pleno do Supremo Tribunal Federal, a mais alta Corte de Justiça do país, julgou em 29 de setembro de 2018 a Ação Direta de

PREÂMBULO: Nós, representantes do povo brasileiro, reunidos em Assembleia Nacional Constituinte para instituir um Estado Democrático, destinado a assegurar o exercício dos direitos sociais e individuais, a liberdade, a segurança, o bem-estar, o desenvolvimento, a igualdade e a justiça como valores supremos de uma sociedade fraterna, pluralista e sem preconceitos, fundada na harmonia social e comprometida, na ordem interna e internacional, com a solução pacífica das controvérsias, promulgamos, sob a proteção de Deus, a seguinte Constituição da República Federativa do Brasil. 
Inconstitucionalidade $n^{\circ} 5257(\mathrm{ADI})^{3}$, do Estado de Rondônia, tendo como Ministro Relator Dias Toffoli, cujo embate jurídico trata de norma estadual que oficializa a Bíblia como livro-base de fonte doutrinária para fundamentar princípios, usos e costumes de comunidades, igrejas e grupos no estado de Roraima.

A Suprema Corte de Justiça julgou inconstitucional o art. $1^{\circ}$ da Lei $\mathrm{n}^{\circ}$ 1.864/08 do Estado de Rondônia. A ementa da ADI supra mencionada pontua que a norma viola os princípios da laicidade, da liberdade de crença e preceitos constitucionais, verbis:

A oficialização da Bíblia como livro-base de fonte doutrinária para fundamentar princípios, usos e costumes de comunidades, igrejas e grupos no Estado de Rondônia implica inconstitucional discrímen entre crenças, além de caracterizar violação da neutralidade exigida do Estado pela Constituição Federal. Inconstitucionalidade do art. $1^{\circ}$ da Lei no $1.864 / 08$ do Estado de Rondônia. (BRASIL, 2018b).

\section{O Ministro Relator Dias Toffoli ao justificar seu voto ressalta o poder} e o dever do Estado de proteger o pluralismo religioso:

Todos os entes federados têm o dever de proteger o pluralismo religioso

EMENTA Ação Direta de Inconstitucionalidade. Norma estadual que oficializa a bíblia como livro-base de fonte doutrinária. Violação dos princípios da laicidade do estado e da liberdade de crença. Procedência. 1. A norma do Estado de Rondônia que oficializa a Bíblia Sagrada como livro-base de fonte doutrinária para fundamentar princípios de comunidades, igrejas e grupos, com pleno reconhecimento pelo Estado, viola preceitos constitucionais. 2. Já sob os primeiros raios da república brasileira se havia consagrado, em âmbito normativo, o respeito à liberdade de crença, e foi sob essa influência longínqua que a Constituição Federal de 1988 fez clarividente em seu texto a proteção a essa mesma liberdade sob as variadas nuances desse direito. 3. A oficialização da Bíblia como livrobase de fonte doutrinária para fundamentar princípios, usos e costumes de comunidades, igrejas e grupos no Estado de Rondônia implica inconstitucional discrímen entre crenças, além de caracterizar violação da neutralidade exigida do Estado pela Constituição Federal. Inconstitucionalidade do art. $1^{\circ}$ da Lei $n^{\circ} 1.864 / 08$ do Estado de Rondônia. 4. A previsão legal de utilização da Bíblia como base de decisões e atividades afins dos grupos religiosos, tornando-as cogentes a "seus membros e a quem requerer usar os seus serviços ou vincular-se de alguma forma às referidas Instituições”, implica indevida interferência do Estado no funcionamento de estabelecimentos religiosos, uma vez que torna o que seria uma obrigação moral do fiel diante de seu grupo religioso uma obrigação legal a ele dirigida. Inconstitucionalidade do art. $2^{\circ}$ da Lei n ${ }^{\circ}$ 1.864/08 do Estado de Rondônia. 5. Procedência da ação para se declarar a inconstitucionalidade do art. $1^{\circ}$ e do art. $2^{\circ}$ da Lei $\mathrm{n}^{\mathrm{o}}$ 1.864/2008 do Estado de Rondônia. Decisão. O Tribunal, por unanimidade, julgou procedente o pedido formulado na ação direta para declarar a inconstitucionalidade do art. $1^{\circ}$ e do art. $2^{\circ}$, ambos da Lei $n^{\circ} 1.864 / 2008$ do Estado de Rondônia, nos termos do voto do Relator. Ausentes, justificadamente, os Ministros Celso de Mello e Carmen Lúcia. Presidência do Ministro Dias Toffoli. Plenário, 20.9.2018. (BRASIL, 2018b). 
dentro de seu território; criar condições para um bom exercício da cidadania nessa seara; zelar pelo princípio da igualdade entre as crenças e, sobretudo, em seu dever de laicidade, se abster de incorporar ideologias religiosas a quaisquer de seus campos de atuação. Assim, nenhum ente da federação está autorizado a incorporar preceitos e concepções, seja da Bíblia ou de qualquer outro livro sagrado, a seu ordenamento jurídico. (BRASIL, 2018b).

Percebe-se que a matéria tratada no acórdão paradigmático, se assemelha com a Lei de Leitura Bíblica, sancionada pela casa legislativa do município de Campina Grande, objeto do presente artigo. A proposição da Leitura Bíblica pela Lei Municipal de $n^{\circ}$ 7.280/2019 direciona a Bíblia como "[...] fonte de conhecimento cultural, geográfico e científico, fatos históricos bíblicos.” (CÂMARA MUNICIPAL DE CAMPINA GRANDE, 2019).

Afinal, por que no entender do legislador municipal apenas a Bíblia seria fonte de conhecimento? O que dizer dos conhecimentos do Judaísmo, do Islamismo, dentre outras. O que dizer ainda, das religiões afro-indígenas, que se apresentam de forma tão marcante em um país de cultura diversificada como o Brasil? Não seriam igualmente importantes?

Ao indicar como única fonte de leitura, a Bíblia Sagrada, o legislador está impedindo que os estudantes da rede de ensino, privada ou pública, de conhecer outras religiões e chegar as suas próprias conclusões acerca de suas opções, inseridos num contexto mais amplo de diversidade religiosa. Nesse caso então, será que é para suprimir o Ensino Religioso das escolas públicas?

O Ensino Religioso integrado aos demais componentes curriculares da educação básica estabelece diálogos entre valores humanos e culturais, no respeito á diversidade cultural religiosa do país, em uma perspectiva educacional fundamentada nas áreas Ciências da Educação e da(s) Religião(ões), em perspectivas interculturais. Estruturado no currículo Educação Básica, os saberes e conhecimentos religiosos, enquanto direitos a aprendizagem, constituem-se em saberes escolares específicos do ER. (HOLMES; PALHETA, 2015, p. 254).

O mais grave, é direcionar a educação religiosa dos outros, segundo suas próprias convicções, o que é inadmissível dentro da perspectiva da laicidade e da neutralidade do Estado democrático de direito. Refletindo sobre isso, lembramos que essa é função de uma confessionalidade de fé, bem como da própria família. Portanto não compete a escola pública oferecer estudos de uma única crença religiosa, com isso estará ferindo o estado laico assim como, os preceitos da legislação. 
A temática do ER nas redes públicas de ensino com direito do educando e como obrigatoriedade de oferta por parte do Estado, está intrinsecamente ligada aos princípios democráticos e da paz, aos direitos civis e políticos de cada cidadão, bem como dos Direitos Humanos. O Brasil é um país que não possui uma religião oficial, mas esforça-se por garantir a todos os seus cidadãos a liberdade de professarem ou não um credo religioso como afirmado no Artigo 5, Inciso VI da sua Constituição de (1988): 'A inviolabilidade da liberdade de consciência e crença, assegurando o livre exercício dos cultos religiosos e a proteção aos locais de culto e suas liturgias.' (HOLMES; PALHETA, 2015, p. 256).

Como relatou o Ministro Toffoli, no caso do estado Rondônia, aqui também implica, salvo melhor juízo, interferência indevida do Estado, fere os preceitos constitucionais da laicidade e da liberdade de crença, como também viola a neutralidade do Estado vindicada no texto Constitucional.

Os direitos do ser humano, à democracia é a paz compõe o tripé de valores indispensáveis na construção da história, bem como do movimento transformador contínuo, que a mesma precisa desenvolver, sob o risco de se tornar anacrônico. Em outras palavras a democracia é a sociedade dos cidadãos e os indivíduos se tornam cidadãos quando lhes são reconhecidos direitos fundamentais; haverá paz estável, uma paz que não tenha a guerra e os diversos tipos de violência como alternativa na solução de conflitos, somente quando existirem cidadãos não mais apenas deste ou daquele Estado, mas do mundo, sem barreiras e sem fronteiras geográficas, políticas, ideológicas, históricas, culturais e religiosas. (HOLMES; PALHETA, 2015, p. 257).

Até aqui fizemos uma contextualização da Lei Municipal 7.280/2019 e da laicidade do estado brasileiro. Passaremos a fazer considerações sobre o ER que está diretamente imbricado neste assunto.

\section{Ensino Religioso}

Historicamente nos últimos 5 séculos, a história do ER, vem juntamente com a história da Educação Brasileira e a História do Brasil, passando por diversas reformas teórico-metodológicas, de viés multicultural. Ao longo da nossa história, educação e religião sempre estiveram presentes. Os 'ranços' da educação religiosa eurocêntrica europeia tem consequências até nos dias atuais. A primeira 'disciplina' chamada de 'instrução Religiosa' foi oficialmente implantada com a publicação do Decreto Imperial n ${ }^{\circ} 7.247 / 1879$ que reformulou o ensino primário, secundário e superior do Brasil. 
$\mathrm{Na}$ Constituição Imperial de 1824, no Art. 5, a “[...] religião católica apostólica romana continuará a ser a religião do Império.” (LOUREIRO; RODRIGUES, 2020). Após a Proclamação da República, em 1889, com o Decreto 119-A, de janeiro/1890, há uma separação entre o Estado e a Religião no Brasil:

[...] Art. $1^{\circ}$ é proibido a autoridade federal, assim como a dos Estados federados, expedir leis, regulamentos ou atos administrativos, estabelecendo alguma religião, ou vedando-a, e criar diferenças entre os habitantes do país, ou nos serviços sustentados à custa do orçamento, por motivos de crenças, ou opiniões filosóficas, ou religiosas. [...] Art.72 $₫ 6^{\circ}[\ldots]$ leigo o ensino ministrado nos estabelecimentos públicos. (BRASIL, 2020b).

Nas décadas seguintes muitas divergências aconteceram envolvendo a laicidade e ensino confessional nas escolas públicas. Embora oficialmente o ER tenha sido excluído na República, poucas instituições seguiram essa legislação segundo a historiografia. Com a Constituição de 1934, se retira o vocábulo Ensino Leigo e se reinclui o Ensino Religioso, de matrícula facultativa para os estudantes, mas como disciplina confessional.

Desde então uma série de encaminhamentos e experiências aconteceram com o ER, com a égide muito presente, da Igreja Católica. As universidades também se empenharam nessa construção, como a de Juiz de Fora, que em junho de 1969, criou o Primeiro Departamento de Ciências das Religiões em nosso país.

Na década de 1980, houve uma efervescência dos movimentos e das mobilizações sociais que culminou na Constituição Cidadã de 1988, que assegura em seu Art. 210 \ $1^{\circ}$ : “O ensino religioso de matrícula facultativa constituirá disciplina dos horários normais das escolas públicas de ensino fundamental." (BRASIL, 2020a).

As transformações no campo educacional dos anos 1990, corroborou com a Lei de Diretrizes e Bases (LDB) no 9394/96, que traz o ER com possibilidades a ser ofertadas como disciplina confessional ou interconfessional. Em julho de $1997^{4}$, com a aprovação da Lei no ${ }^{\circ}$ 9.475,

\footnotetext{
$4 \quad$ Esta Lei provocou uma significativa mudança de paradigmas, viabilizando o respeito à diversidade cultural religiosa do Brasil no contexto escolar, tendo em vista o estudo das diversas e religiosidades, que até então não eram reconhecidas, sendo ignoradas pela comunidade escolar. (Livro: Ensino Religioso na Educação Básica: fundamentos epistemológicos e curriculares 2015) - Obra comemorativa dos 20 anos do FONAPER.
} 
conhecida como a Lei do Ensino Religioso, o Art. 33 da LDB, passa a ter uma nova redação:

O ensino religioso, de matrícula facultativa, é parte integrante da formação básica do cidadão e constitui disciplina dos horários normais das escolas públicas de ensino fundamental, assegurado o respeito à diversidade cultural religiosa do Brasil, vedadas quaisquer formas de proselitismo.

$\int 1$ Os sistemas de ensino regulamentam os procedimentos para a definição do conteúdo do ensino religioso e estabelecerão as normas para a habilitação e admissão dos professores.

$\int 2$ Os sistemas de ensino ouvirão entidade civil, constituída pelas diferentes denominações religiosas, para a definição dos conteúdos do ensino religioso. (BRASIL, 1997).

A LDB preconiza o respeito à laicidade do Estado Brasileiro. Conforme a análise de Freitas (2018, p. 38), existe certa inércia do MEC quanto aos $\int 1^{\circ}$ e $\int 2^{\circ}:$

Conforme se observa no texto da lei, o viés do ensino religioso toma um caráter não confessional, alerta que a disciplina é parte da formação básica dos/das cidadãos/cidadãs e ainda adverte sobre o proselitismo. No entanto, os grandes problemas referentes à disciplina dizem respeito ao $\int 1^{\circ}$ e $\int 2^{\circ}$ da lei acima citada; pois o MEC não tomou para si a responsabilidade de orientar sobre os procedimentos pedagógicos e metodológicos, deixando a disciplina solta, sem sequer procurar ouvir o Fórum representativo do ensino religioso, que havia se esforçado para escrever os parâmetros curriculares nacionais da disciplina. (BRASIL, 1996).

O Fórum que se refere o autor é o Fórum Nacional Permanente de Ensino Religioso (FONAPER ${ }^{5}$ ) que tem uma importância fundamental para a história do ER brasileiro. Fundado em setembro 1995, em Florianópolis/SC, vem atuando na perspectiva de acompanhar, organizar e subsidiar o esforço de professores, pesquisadores, sistemas de ensino e associações na efetivação do Ensino Religioso como componente curricular.

Fórum Nacional Permanente de Ensino Religioso É uma associação civil de direito privado, de âmbito nacional, sem vínculo político-partidário, confessional e sindical, sem fins econômicos, que congrega, conforme seu estatuto, pessoas jurídicas e pessoas naturais identificadas com o Ensino Religioso, sem discriminação de qualquer natureza. É, portanto, um espaço de discussão e ponto aglutinador de ideias, propostas e ideais na construção de pareceres concretos para a operacionalização do Ensino Religioso na escola. (www.fonaper.com.br). 
Em 1997, o Ministério da Educação (MEC) criou os Parâmetros Curriculares Nacionais (PCNs), sem incluir ER no conjunto dos componentes curriculares. Coube ao FONAPER a iniciativa histórica de criar os Parâmetros Curriculares Nacionais do Ensino Religioso (PCNER), que continua sendo referência significativa até hoje, na formação dos educadores. De acordo com este, é importante à compreensão dos conhecimentos religiosos para dialogar com as tradições culturais e religiosas.

Por tradições religiosas, aqui compreende-se a sistematização do fenômeno religioso, a partir de suas raízes orientais; ocidentais, africanas e indígenas que exige para o seu ministério (ou mister), um profissional de educação sensível à pluralidade, consciente da complexidade sociocultural da questão religiosa e que garanta a liberdade religiosa do educando sem proselitismo. (FORUM ..., 2012, p. 13).

Com a Resolução CNE/CEB no 2, em 1998, das Diretrizes Curriculares Nacionais para o Ensino Fundamental, se tem a instituição da "Educação Religiosa, na forma do artigo 33 da Lei no 9.394, de 20 de dezembro de 1996" entre as dez áreas de conhecimento da base nacional comum.

Em 2010, a Resolução do CNE/CEB no 4/2010, instituiu as Diretrizes Curriculares Nacionais Gerais para a Educação Básica, e o Ensino Religioso se manteve na Base Nacional Comum:

Art. 14

$\int 1^{\circ}$ Integram a base nacional comum:

a) a Língua Portuguesa;

b) a Matemática;

c) o conhecimento do mundo físico, natural, da realidade social e política, especialmente do Brasil, incluindo-se o estudo da História e das Culturas Afro Brasileira e Indígena,

d) a Arte, em suas diferentes formas de expressão, incluindo-se a música;

e) a Educação Física;

f) o Ensino Religioso. (BRASIL, 2010a, grifo nosso).

No mesmo ano de 2010, a Resolução CNE/CEB n 7 , que trata sobre as Diretrizes Curriculares Nacionais para o Ensino Fundamental de 9 (nove) anos, institui o ER como uma das cinco áreas de conhecimento:

Art. 15. Os componentes curriculares obrigatórios do Ensino Fundamental serão assim organizados em relação às áreas de conhecimento: 
I - Linguagens:

a) Língua Portuguesa;

b) Língua Materna, para populações indígenas;

c) Língua Estrangeira moderna;

d) Arte; e

e) Educação Física;

II - Matemática;

III - Ciências da Natureza;

IV - Ciências Humanas:

a) História;

b) Geografia;

V - Ensino Religioso. (BRASIL, 2010b, grifo nosso).

O CNE, em outubro de 2019, no Parecer CNE/CEB nº 8, altera o artigo 15 da Resolução $\mathrm{CNE} / \mathrm{CEB} n^{\circ} 7$, dá nova redação o ER, que deixa de ser Área de Conhecimento e passa a ser Componente Curricular:

Art. 15 Os componentes curriculares obrigatórios do Ensino Fundamental serão assim organizados em relação às áreas de conhecimento:

I - Linguagens:

a) Língua Portuguesa;

b) Língua Materna, para populações indígenas;

c) Língua Estrangeira moderna;

d) Arte; e

e) Educação Física;

II - Matemática;

III - Ciências da Natureza;

IV - Ciências Humanas:

a) História;

b) Geografia;

c) Ensino Religioso. (BRASIL, 2019, grifo nosso).

Em 2017, a Resolução CNE/CP n ${ }^{\circ}$ 2, que institui e orienta a implantação da Base Nacional Comum Curricular $\left(\mathrm{BNCC}^{6}\right)$, apresenta as seguintes competências do ER:

\footnotetext{
Base Nacional Comum Curricular que é um documento de caráter normativo que define o conjunto orgânico e progressivo de aprendizagens essenciais que todos os estudantes devem desenvolver ao longo das etapas e modalidades da Educação Básica, de modo a que tenham assegurados seus direitos de aprendizagem e desenvolvimento, em conformidade com o que preceitua o Plano Nacional de Educação (PNE). Este documento aplicase exclusivamente à educação escolar, tal como a define o $\int 1^{\circ}$ do Artigo $1^{\circ}$ da Lei de Diretrizes e Bases da Educação Nacional (LDBEN, Lei no 9.394/96), e está orientado pelos princípios éticos, políticos e estéticos que visam à formação humana integral e à construção de uma sociedade justa, democrática e inclusiva, como fundamentado nas Diretrizes Curriculares Nacionais da Educação Básica. (BRASIL, 2017b).
} 
a. Conhecer os aspectos estruturantes das diferentes tradições/movimentos religiosos e filosofias de vida, a partir de pressupostos científicos, filosóficos, estéticos e éticos;

b. Compreender, valorizar e respeitar as manifestações religiosas e filosofias de vida, suas experiências e saberes, em diferentes tempos, espaços e territórios; c. Reconhecer e cuidar de si, do outro, da coletividade e da natureza, enquanto expressão de valor da vida;

d. Conviver com a diversidade de identidades, crenças, pensamentos, convicções, modos de ser e viver;

e. Analisar as relações entre as tradições religiosas e os campos da cultura, da política, da economia, da saúde, da ciência, da tecnologia e do meio ambiente; f. Debater, problematizar e posicionar-se frente aos discursos e práticas de intolerância, discriminação e violência de cunho religioso, de modo que se assegure assim os direitos humanos no constante exercício da cidadania e da cultura de paz [...]

$\int 2^{\circ}$ O Ensino Religioso, conforme prevê a Lei 9.394/1996, deve ser oferecido nas instituições de ensino e redes de ensino públicas, de matrícula facultativa aos alunos do Ensino Fundamental, conforme regulamentação e definição dos sistemas de ensino. (BRASIL, 2017b, Art. 14).

Com a homologação da BNCC, pela Portaria MEC n 1.570 , de 20 de dezembro de 2017, o ER tem os seguintes objetivos:

$[\ldots]$

a) Proporcionar a aprendizagem dos conhecimentos religiosos, culturais e estéticos, a partir das manifestações religiosas percebidas na realidade dos educandos;

b) Propiciar conhecimentos sobre o direito à liberdade de consciência e de crença, no constante propósito de promoção dos direitos humanos;

c) Desenvolver competências e habilidades que contribuam para o diálogo entre perspectivas religiosas e seculares de vida, exercitando o respeito à liberdade de concepções e o pluralismo de ideias, de acordo com a Constituição Federal;

d) Contribuir para que os educandos construam seus sentidos pessoais de vida a partir de valores, princípios éticos e da cidadania (BRASIL, 2017b, p. 434).

Quando se fala dos conhecimentos religiosos, no direito às liberdades, na promoção dos direitos humanos, no diálogo, nos princípios éticos e estéticos garantindo assim ampliação dos laços com as mais diversas culturas religiosas sem distinção alguma, bem como na laicidade do Estado brasileiro fica muito evidente que: 


\section{Lusival Antonio Barcellos; Maria José Torres Holmes}

\section{Marlene Pereira Borba Cabú; Ana Paula Rodrigues Cavalcanti}

O conhecimento religioso, objeto da área de Ensino Religioso, é produzido no âmbito das diferentes áreas do conhecimento científico das Ciências Humanas e Sociais, notadamente da(s) Ciência(s) da(s) Religião(ões). Essas Ciências investigam a manifestação dos fenômenos religiosos em diferentes culturas e sociedades enquanto um dos bens simbólicos resultantes da busca humana por respostas aos enigmas do mundo, da vida e da morte. De modo singular, complexo e diverso, esses fenômenos alicerçaram distintos sentidos e significados de vida e diversas ideias de divindade(s), em torno dos quais se organizaram cosmovisões, linguagens, saberes, crenças, mitologias, narrativas, textos, símbolos, ritos, doutrinas, tradições, movimentos, práticas e princípios éticos e morais. Os fenômenos religiosos em suas múltiplas manifestações são parte integrante do substrato cultural da humanidade. (BRASIL, 2017b, p. 436).

A BNCC, propõe que o ER trate "[...] os conhecimentos religiosos a partir de pressupostos éticos e científicos, sem privilégio de nenhuma crença ou convicção. Isso implica abordar esses conhecimentos com base nas diversas culturas e tradições religiosas, sem desconsiderar a existência de filosofias de vida." (BRASIL, 2017b).

Em 2018, a Resolução CNE/CP nº 05/2018, que institui as Diretrizes Curriculares Nacionais para o curso de licenciatura em Ciências da Religião (DCNCR), nas modalidades tanto presencial, como semipresencial e a distância, supri uma carência que décadas esta área de conhecimento aguardava do MEC. Trata-se de base jurídica fundamental para o ER por:

[...] constitui-se como habilitação em nível de formação inicial para o exercício da docência do Ensino Religioso na Educação Básica.

Parágrafo Único - Para além da docência, o licenciado em Ciências da Religião poderá atuar como pesquisador, consultor e assessor em espaços não formais de ensino, em instituições públicas e privadas, organizações não governamentais e entidades confessionais. (BRASIL, 2019, p. 1).

Muitas legislações acabam sem eficácia por não haver as condições necessárias para sua implantação. É o caso das DCNs em Ciências da Religião, que necessitam do MEC uma política de incentivo, disponibilizando recursos financeiros, para as Universidades Públicas ofertarem cursos de Licenciatura em Ciências da Religião presenciais, semipresenciais ou Estudo a Distância (EAD).

O formação inicial beneficiará o/a docente para exercer o seu cargo de professor de ER conforme o Art. 11: "Pelo prazo de 8 (oito) anos, a contar da publicação destas DCNs, a habilitação para a docência do Ensino Religioso 
para portadores de outras licenciaturas reger-se-á pelo disposto no artigo 15 da Resolução CNE/CP no 2, de $1^{\circ}$ de julho de 2015.” (BRASIL, 2019, p. 3).

De acordo com as DCNs, a formação continuada para professores de ER é essencial, a fim de dar suporte não somente teórico, mas também prático com a finalidade de fortalecer o processo de ensino e da aprendizagem. Essa formação dar-se-á através do Art. 12, em que assegura: "A formação continuada para docentes do Ensino Religioso deve atender o disposto nos artigos 15 e 17 do Capítulo VI da Formação Continuada dos profissionais do magistério da Resolução CNE/CP n ${ }^{\circ} 2$, de $1^{\circ}$ de julho de 2015.” (BRASIL, 2019, p. 3).

Por outro lado, ressalta-se ainda que a LDB garante a formação continuada aos professores de qualquer componente curricular através do Art. 61:

A formação de profissionais da educação, de modo a atender aos objetivos dos diferentes níveis e modalidades de ensino e às características de cada fase do desenvolvimento do educando, terá como fundamentos: (Regulamento).

Art. 61. Consideram-se profissionais da educação escolar básica os que, nela estando em efetivo exercício e tendo sido formados em cursos reconhecidos. (BRASIL, 1996).

Diante do que foi exposto, compete à escola cumprir a legislação vigente tendo na sua equipe o profissional de ER por ser muito essencial para o ensino e na aprendizagem ("Para isso, as Ciências da Religião podem servir de locus de pesquisa e formação, contribuindo na qualificação de docentes e também gestores educacionais [...]" (BAPTISTA, 2020, p. 15, grifo nosso). O professor do ER desperta para a solidariedade, cultiva a esperança, suscita o gosto pela vida!

As Resoluções e os Pareceres, fortalecidos pelo FONAPER, a Rede Nacional de Licenciaturas em Ensino Religioso (RELER), conjuntamente com as universidades, dentre outras instituições buscam novos ideais para que este componente curricular se fortaleça e se estabeleça em todas as escolas públicas desse país, através de um ER não confessional.

\section{Por que o Ensino Religioso nas escolas?}

Porque objetiva desenvolver ações de relevância junto à comunidade escolar, com a finalidade de desmistificar o preconceito, o desrespeito, a intolerância religiosa e cultural, o feminicídio, a discriminação, o bullying que tanto dificulta as relações de diálogo entre as pessoas. 
[...] o Ensino Religioso deve ser ministrado com base nos objetivos da formação básica do cidadão, buscando desenvolver o aprendizado da leitura, da escrita e do cálculo. E também deve propiciar a compreensão do ambiente natural e social, do sistema político, da tecnologia, das artes e dos valores da sociedade. (BRASIL, 2018c, p. 7).

Dando continuidade, o Parecer CNE/CP n 12/2018 acrescenta que o Ensino Religioso necessita:

[...] favorecer o exercício da liberdade de pensamento, de crença e de convicção. Considerando os movimentos, tradições religiosas e filosofias seculares de vida, o estudo das diferentes crenças é uma das formas privilegiadas de promover a liberdade de concepções e o exercício da cidadania, fundamento do estado laico e democrático. É nesse sentido que o Ensino Religioso pode se tornar um baluarte da liberdade, congregando indistintamente os valores que prefiguram juridicamente a expressão religiosa conforme o espírito da nossa Constituição de 1988, quais sejam: a liberdade de crença, a liberdade de culto, e a liberdade de organização religiosa. (BRASIL, 2018c, p. 9).

Do ponto de vista da escola como uma instituição pluralista, o foco desse componente curricular objetiva: Despertar nos estudantes a descoberta de novos valores que propicia a esses, se tornarem, sujeitos da sua própria construção do conhecimento, sujeito da história e da sociedade em que vive. $\mathrm{O}$ seu aprendizado em sala de aula possibilita a esses/as descobrir o verdadeiro sentido da vida, que vem completar a sua formação ética, estética e cidadã, respeitando as diferenças existentes no contexto escolar. Viktor Frankl (1984, p. 76) afirma:

Ao declarar que o ser humano é uma criatura responsável e precisa realizar o sentido potencial de sua vida, quero salientar que o verdadeiro sentido da vida deve ser descoberto no mundo, e não dentro da pessoa humana ou de sua psique, como se fosse um sistema fechado. Chamei esta característica constitutiva de "a autotranscedência da existência humana". Ela denota o fato de que ser humano sempre aponta e se dirige para algo ou alguém diferente de si mesmo - seja um sentido a realizar ou outro ser humano a encontrar. Quanto mais a pessoa esquecer de si mesma - dedicando-se a servir uma causa ou a amar outra pessoa - mais humana será e mais se realizará. O que se chama de autor-realização não é de modo algum um objetivo atingível, pela simples razão de que quanto mais a pessoa se esforçar, tanto mais deixará de atingi-lo. Em outras palavras, autorrealização só é possível como um efeito colateral da autotranscedência. 
É importante reforçar que o ER, enquanto componente curricular, contribui para o estado democrático de direito, além de ser um facilitador das liberdades e valores, promove ainda uma cultura de paz, que dialoga com seus pares, desenvolve trabalho coletivo, compreendendo toda comunidade escolar.

Segundo Berger (2019, p. 20), "É trabalhando juntos que os homens fabricam instrumentos, inventam línguas, aderem os valores, concebem as instituições, e assim por diante[...] Destarte este autor destaca ainda que: "A sociedade é, portanto, não só resultado da cultura, mas uma condição necessária dela." (BERGER, 2019, p. 21). Essa é a grande diferença desse componente curricular no chão das escolas, que acontece a partir de uma reflexão sobre a sua nova identidade que se dá através de um novo imaginário.

Holmes (2016, p. 83) assevera: "Pensar o ER atualmente é buscar um novo paradigma, outra identidade, que é uma questão retomada pelos diversos segmentos da sociedade a partir da visão antropológica, sociológica, histórica e, principalmente científica." Esta é a base que fundamenta o ER em nossas escolas públicas.

\section{Qual a situação do Ensino Religioso no Brasil hoje?}

Embora o ER seja um componente curricular obrigatório a ser oferecido em todas as escolas públicas do ensino fundamental, de fato, ainda não é o que acontece na grande maioria das redes de ensino dos municípios e dos estados brasileiros. O mais grave é que esta realidade vem se protelando a mais de duas décadas.

Com a homologação da BNCC, em dezembro de 2017, um novo horizonte na educação brasileira se vislumbrava para a construção dos currículos no ER e no Ensino Fundamental. No dia da homologação o então Ministro da Educação, no seu discurso assegurou que:

Estamos viabilizando a construção de uma nova educação no Brasil, que seja inclusiva, que gere equidade e oportunidade para todos, para que o filho do pobre possa ter acesso ao mesmo conteúdo de qualidade e de etapas da sua vida educacional disponível aos estudantes de classe média ou mais ricas. (MENDONÇA FILHO, Informação verbal, Brasília, dez. 2017).

É importante entender a conjuntura política daquele momento. O presidente da república, Michel Temer havia sido empossado em agosto de 2016. Em 2018, seria um ano de eleição e muitas especulações políticas já estavam sendo orquestradas. Somada a isso, em setembro de 2017, o Supremo 
Tribunal Federal julgou a ADI $4439^{7}$, mas ainda se aguardava a publicação do acórdão do Ministro Alexandre de Moraes, que só ocorreu em junho de 2018.

[...] Ação direta julgada improcedente, declarando-se a constitucionalidade

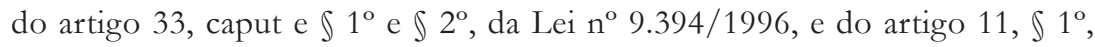
do acordo entre o Governo da República Federativa do Brasil e a Santa Sé, relativo ao Estatuto Jurídico da Igreja Católica no Brasil, e afirmando-se a constitucionalidade do ensino religioso confessional como disciplina facultativa dos horários normais das escolas públicas de ensino fundamental. (BRASIL, 2018c, p. 8).

Porém, na mesma Portaria MEC n ${ }^{\circ} 1.570 / 2017$ que homologa a BNCC, tem um artigo com a seguinte redação:

Após a publicação do Acórdão do Supremo Tribunal Federal no julgamento da Ação Direta de Inconstitucionalidade no 4439, o Ministro da Educação poderá solicitar ao Conselho Nacional de Educação reavaliação do disposto para o ensino religioso na BNCC. (BRASIL, 2017c, Art. $2^{\circ}$ ).

Este artigo, desde então, tem sido nefasto para o ER. Isto porque, em abril de 2018, o MEC instituiu o Programa de Apoio à Implementação da Base Nacional Comum Curricular (Pro BNCC), com o objetivo de apoiar os municípios e os estados na elaboração e implementação dos seus currículos alinhados à BNCC. Foi destinado mais de $\mathrm{R} \$ 100$ milhões para a implementação da BNCC.

Entretanto, mesmo estando na BNCC, o ER ficou fora oficialmente do Programa de Apoio à Implementação da Base Nacional Comum Curricular (ProBNCC), que estabelece as diretrizes, parâmetros e critérios para sua

\footnotetext{
Não obstante, em 13 de novembro de 2008 foi assinado o "Acordo entre o Governo da República Federativa do Brasil e a Santa Sé, relativo ao Estatuto Jurídico da Igreja Católica no Brasil". O $\int 1^{\circ}$ do artigo 11 dispõe que "O ensino religioso, católico e de outras confissões religiosas, de matrícula facultativa, constitui disciplina dos horários normais das escolas públicas de ensino fundamental, assegurado o respeito à diversidade cultural religiosa do Brasil, em conformidade com a Constituição e as outras leis vigentes, sem qualquer forma de discriminação." Em decorrência desse acordo, e por entender que o ensino religioso só poderia ser de natureza não-confessional, a Procuradoria Geral da República ingressou com a Ação Direta de Inconstitucionalidade $n^{\circ} 4.439$ no Supremo Tribunal Federal em 2010. O objeto da ação era o artigo 33, caput e $\int 1^{\circ}$ e $\int 2^{\circ}$, da Lei no 9.394/1996 (Lei de Diretrizes e Bases da Educação Nacional - "LDB"), e o artigo 11, $\int 1^{\circ}$ do Acordo Brasil-Santa Sé, aprovado por meio do Decreto Legislativo nº 698/2009 e promulgado por meio do Decreto $\mathrm{n}^{\circ} 7.107 / 2010$. (BRASIL, 2018c, p. 8).
} 
implementação. (BRASIL, 2018d). Todas as áreas tiveram treinamentos com passagens e hospedagens, bolsas mensais, orientações e articulações para realizarem as propostas curriculares. O ER nada disso teve.

O 'efeito cascata' que isso provocou nos municípios e nos estados é incalculável. Os Secretários, que não tinham na matriz curricular o ER, não precisando enviar um representante do ER para o ProBNCC, continuaram negligenciando o cumprimento da Lei, no que se refere ao ER.

O MEC continua tendo uma posição diferenciada por não adotar uma ação equânime nas áreas de conhecimento e não inclui o ER. Fica evidente que é uma opção política equivocada, prejudicando toda uma área que é importantíssima na formação humana e cidadã do estudante.

Como dissemos anteriormente, isso já havia ocorrido na década de 1990, com os PCNs, embora em outro contexto. O ER mostrou mais uma vez, a sua resistência e a sua perseverança. Onde foi possível professores, estudantes, membros do FONAPER e demais interessados pela causa ER, não mediram esforços e apresentaram a proposta do ER nos Estados e Municípios. Esses profissionais vão encontrando oportunidades para superar as barreiras e articularem as ações para o ER se efetivar nos sistemas de Ensino.

Em 2020, estão acontecendo nos estados e municípios as formações do Pro BNCC para essa ação chegar até as escolas. Na Paraíba a equipe de voluntários do ER se integrou na Comissão responsável pela elaboração da Proposta Curricular da Paraíba (PCPB) e participou ativamente de todas as etapas como voluntários. É importante frisar que todo trabalho na produção de material desses voluntários, precisou ser feito em tempo record e seguindo o cronograma da PCPB. Isso na prática é ter que se adequar ao calendário que foi estabelecido. E mais, estar continuamente se disponibilizando e entrando em contato permanente para acompanhar as etapas.

Para a formação chegar até as escolas da Paraíba, se programou primeiramente, 12 polos para atingir as 16 Gerências Regionais de Ensino. Nessa configuração congregam os 223 municípios paraibanos que estão em seu entorno. Foram programadas duas etapas presenciais, com intervalos para os professores interagirem via EAD. Várias mudanças foram acontecendo e de fato apenas duas formações ocorreram em dois polos: Campina Grande e Patos. Nessas formações estiveram, presentes os representantes das escolas estaduais e das secretarias municipais circunvizinhas. O objetivo da formação foi capacitar professores para serem multiplicadores junto aos colegas, na escola. 


\section{Lusival Antonio Barcellos; Maria José Torres Holmes}

Marlene Pereira Borba Cabú; Ana Paula Rodrigues Cavalcanti

O que acontece de fato nessas formações é uma grande ausência do professor de ER. Primeiro porque a maioria das escolas não tem esse profissional. Isso traz um outro desdobramento: os secretários municipais e os diretores de escolas priorizam os componentes clássicos e não enviam um representante do ER para a formação. Dessa maneira o ER fica excluídos da educação.

Entretanto, é fundamental que os Sistemas de Ensino Municipais e Estadual tenham na matriz curricular a oferta do ER em todo o Ensino Fundamental. Concomitantemente é necessário haver, não apenas a contratação de professores de ER, mas que promovam concursos públicos para que este componente curricular tenha profissionais concursados, saudando uma dívida educacional de mais de duas décadas. Constata-se que essa ainda é uma regra geral em praticamente todo Brasil, com raras exceções como o Estado de Santa Catarina, que já oferece concurso para professor efetivo de ER, desde 2001.

Hoje, em termos de regiões brasileiras, temos na Paraíba alguns municípios com professor concursado em ER, como é o caso de Gurinhém, Patos, D. Inês, dentre outros. Também é o caso do município de Natal, no estado Rio Grande do Norte. Por outro lado, na Região Norte, os municípios de Manaus-AM e Belém-PA também estão em conformidade com a Lei. Esperamos que as autoridades cumpram com o que preconiza a legislação educacional e promovam concursos públicos para essa demanda histórica do ER. Há certa expectativa dos municípios e dos estados, contratem profissionais criando um núcleo específico com uma equipe de execução e formação do ER.

Em todo Brasil, estão acontecendo audiências públicas em 2020, com os entes responsáveis pela implementação do ER, envolvendo Ministério Público, Secretários/as de Educação, universidades, FONAPER, União Nacional do Dirigentes Municipais de Educação (UNDIME), União Nacional dos Conselhos Municipais de Educação (UNCME) e demais instituições para efetivarem ações para a implementação do ER, não confessional.

\section{Considerações Finais}

No atual contexto, o ER necessita ganhar visibilidade e consistência entre os educandos, os professores, os gestores, a comunidade escolar, as famílias, as esferas educacionais e sociais. O termo ER é facilmente associado a uma religião ou a aula de religião e isso é disseminado para a população causando um equívoco do seu objeto de estudo. Há professores 
sem Licenciatura em Ciências das Religiões, que precisam complementar a carga horária na escola e dão aula de ER sem formação ideal e acabam dando 'aula de religião' em sala de aula.

Constata-se também que há setores da sociedade interessados em um ER confessional, bem como introduzir estudos de uma confissão religiosa nas escolas públicas. O Cristianismo é a religião predominante no Brasil e há interesse dos líderes religiosos de manter esse status quo.

Observa-se que, em cada cultura religiosa existem suas normas de valores e essas se apresentam com ensinamentos para a construção da cidadania e da cultura de paz. É onde o fazer pedagógico espelha para educandos/as, a forma de vida desses líderes espirituais, e ao mesmo tempo transmitem suas grandes experiências sobre as vivências de atitudes e valores; de fraternidade e amor ao próximo, independente de credo religioso.

Qualquer manifestação religiosa existente na escola precisa ser acolhida, uma vez que não se pode ferir a liberdade de consciência e de crenças das pessoas. É de fundamental importância que os discentes reconheçam quais os valores de sua tradição religiosa para poder entender os valores da tradição religiosa do outro e assim respeitar. Esse encantamento proporciona aos docentes e discentes, oportunidades de conhecimento para trilhar caminhos através da escuta, do diálogo e do respeito. O ER tem uma abrangência ampla e envolve valores, partilhas, sentimentos, solidariedade e apresenta grande aceitação nas escolas, conforme revelam pesquisas na área, possibilitando muitas aprendizagens, que são essenciais na vida e na formação dos estudantes.

Instituições como o FONAPER tem um legado diferenciado no ER. A cada ano, esse Fórum realiza um grande evento específico sobre o Ensino Religioso, tendo como foco gestores, pesquisadores, estudantes e demais interessados, sobretudo, os professores do Ensino Religioso. Em novembro de 2019, organizou em Curitiba-PR, junto com instituições parceiras, o X Congresso Nacional de Ensino Religioso (CONERE), o XIV Congresso Internacional de Teologia da PUCPR, o II Congresso de Pós-Graduação em Teologia (PPGT/PUCPR) e II Congresso Latino-Americano de Educação e Ciências da Religião (CLAECIR). Em setembro de 2020, está previsto a realização do XVI Seminário Nacional de Formação de Professores do Ensino Religioso (SEFOPER), na Pontifícia Universidade Católica de Minas Gerais, em Belo Horizonte - MG.

O FONAPER foi a instituição responsável pela inclusão e pela redação do currículo de ER na BNCC e pela redação das DCNs do curso 
de licenciatura em Ciências da Religião. No site desse Fórum, o leitor/a encontra contribuições para aprofundar a temática sobre o ER, para conhecer a legislação e experiências inéditas desse componente curricular, para dialogar com professores, partilhar experiências, ficar informado/a dos eventos científicos e do que está acontecendo no Brasil e na América Latina. O seu associado tem um tratamento especial por ser um profissional que exerce um protagonismo de uma proposta pedagógica amorosa, humanitária e solidária.

Sintetizando esta reflexão deixamos algumas perguntas: Que escola nós temos? Que escola nós queremos? Por que não se cumpre a Carta Magna Brasileira e a legislação de ensino vigente? A Lei 7.280 de 17 de julho de 2019, amplamente tratada ao longo desse artigo, afronta e desrespeita toda uma construção de aproximadamente três décadas do ER não confessional e propõe a "Leitura da Bíblia" nas escolas privadas e públicas do Município de Campina Grande.

Estamos aqui, para com a legislação vigente superar essa nova onda de Pós-Colonialidade (GONZALEZ; IAMAMOTO; CRUZ, 2019). Nosso país adota os princípios da laicidade e por isso reafirmamos que estamos vigilantes no cumprimento das leis educacionais, na defesa do ER não confessional e da laicidade do Estado Brasileiro.

\section{Referências}

BAPTISTA, Paulo Agostinho Nogueira. Ciências da Religião e Ensino Religioso: o desafio histórico da formação docente de uma área de conhecimento. Rever, v. 15, n. 2, p. 107 125. Disponível em: zhttps://revistas.pucsp.br/rever/article/view/26189/18851. Acesso em: 20 mar. 2020.

BERGER, Peter Ludwig. O Dossel Sagrado: elementos para uma teoria sociológica da religião; (Trad. José Carlos Barcellos). São Paulo: Paulus, 2019.

BRASIL. [Constituição (1988)]. Constituição da República Federativa do Brasil. Promulgada em 5 de outubro de 1988. Brasília: Senado Federal, Serviço Gráfico.

Disponível em: http://www.planalto.gov.br/ccivil_03/constituicao/constituicao.htm. Acesso em: 11 mar. 2020a.

BRASIL. Decreto n $^{\circ}$ 119-A, de 07 de janeiro de 1989. Disponível em: http://www. planalto. gov.br/ccivil_03/decreto/1851-1899/D119-A.htm. Acesso em: 15 mar. 2020b.

BRASIL. Parecer CNE/CEB Nº:8/2019. Altera o artigo 15 da Resolução CNE/CEB no 7, de 14 de dezembro de 2010, que fixa Diretrizes Curriculares Nacionais para o Ensino Fundamental de 9 (nove) anos. Disponível em: http://portal.mec.gov.br/index.php? option=com_docman\&view $=$ download\&alias $=138411$-pceb008-19\&category_slug=janeiro2020\&Itemid=30192. Acesso em: 18 nov. 2019. 
BRASIL. Resolução CNE/CP n ${ }^{\circ}$ 5, de 28 de dezembro de 2018. Institui as Diretrizes Curriculares Nacionais em Ciências da Religião/Ensino Religioso. Brasília/DF, 2018a.

BRASIL.STF: Ação Direta de Inconstitucionalidade - ADI 8621989-60.2015.1.00.0000 RO - RONDÔNIA 8621989-60.2015.1.00.0000. Brasília/DF, 2018b.

BRASIL. Parecer CNE/CP no 12/2018, aprovado em 2 de outubro de 2018. Institui as Diretrizes Curriculares Nacionais para os cursos de licenciatura em Ciências da Religião. BRASÍLIA/DF, 2018c.

BRASIL. Portaria MEC n $\mathbf{n}^{\mathbf{0}}$ 331, de 05 de abril de 2018. Institui o Programa de Apoio à Implementação da Base Nacional Comum Curricular - ProBNCC e estabelece as diretrizes, parâmetros e critérios para sua implementação. Brasília/DF, 2018d.

BRASIL. Resolução CNE/CP $\mathbf{n}^{\mathbf{0}}$ 2, de 22 de dezembro de 2017. Institui e orienta a implantação da Base Nacional Comum Curricular. Brasília/DF, 2017a.

BRASIL. MEC. Base Nacional Comum Curricular. BNCC. Brasília/DF, 2017b.

BRASIL. Portaria MEC n 1.570, de 20 de dezembro de 2017. Brasília/DF, 2017c.

BRASIL. Resolução CNE/CEB no 4, de 13 de julho de 2010. Define Diretrizes Curriculares Nacionais Gerais para a Educação Básica. Brasília/DF, 2010a.

BRASIL. Resolução CNE/CEB n ${ }^{\mathbf{0}}$ 7, de 14 de dezembro de 2010. Fixa Diretrizes Curriculares Nacionais para o Ensino Fundamental de 9 (nove) anos. Brasília/DF, 2010b.

BRASIL. MEC. Nova redação do Art. 33 da Lei 9394/96. Lei nº 9475/97, de 22 de julho de 1997. Brasília: Diário Oficial da União, de 23 de julho de 1997, Seção I. Brasília/DF.

BRASIL. MEC. Lei de Diretrizes e Bases da Educação Nacional Lei nº. 9394/96, de 20 de dez. 1996. Diário Oficial da União, no 248 de 23. 12. 1996. Seção I. Brasília/DF.

CÂMARA MUNICIPAL DE CAMPINA GRANDE. Lei $\mathbf{n}^{\mathbf{0}} \mathbf{7 . 2 8 0}$ de 17 de julho de 2019, aprovada pela Câmara de Vereadores de Campina Grande - PB. Disponível em: http://blogs.jornaldaparaiba.com.br/plenopoder /2019/09/06/romero-sanciona-lei-quepropoe-leitura-biblica-em-escolas-publicas-de-campina-grande/. Acesso em: 11 out. 2019.

CECCHETTI, Élcio. A laicização do ensino no Brasil (1889-1934). 2016. 322 f. Tese (Doutorado em Educação) - Universidade Federal de Santa Catarina, Florianópolis, 2016.

FÓRUM NACIONAL PERMANENTE DO ENSINO RELIGIOSO. Parâmetros

Curriculares Nacionais: Ensino Religioso. 3. ed. São Paulo: Editora Ave Maria, 2012.

FRANKL, Viktor Emil. Em Busca do Sentido da Vida. Petrópolis, RJ: Vozes, 2020.

FREITAS, Eliane Maura Littig Milhomem de. Bem-me-quer, Malmequer: um estudo sobre a presença do ensino religioso na Base Nacional Comum Curricular. São Paulo, 2018. 237 f. Tese (Doutorado em Ciências da Religião) - Pontifícia Universidade Católica de São Paulo, São Paulo, 2018.

GONZALEZ, Maria Victória Espiñeira; IAMAMOTO, Sue; CRUZ, Danilo Uzêda da (org.). Democracia na América Latina 2 [recurso eletrônico]: descolonização, territórios 
e horizontes. - Feira de Santana: Editora Zarte; Argentina: Clacso, 2019. 342 p. il. E-book. Disponível em: file:///D:/Users/Lusival/Downloads /livro\%20final_final.pdf. Acesso em: 16 mar. 2019.

HOLANDA, Ângela Maria Ribeiro. Ensino Religioso e os direitos de aprendizagem e desenvolvimento nos anos iniciais do ensino fundamental. In: POZZER, Adecir et al. Ensino religioso na educação básica: fundamentos epistemológicos e curriculares. Florianópolis, SC: Saberes em Diálogo, 2015. p. 287-299.

HOLMES, Maria José Torres. Ensino Religioso: esperanças e desafios - reflexões da práxis no cotidiano escolar. Florianópolis, SC: Saberes em Diálogo, 2016.

HOLMES, Maria José Torres. PALHETA, Francisco. Ensino religioso no currículo da educação básica. In: POZZER; Adecir et al. Ensino religioso na educação básica: fundamentos epistemológicos e curriculares. Florianópolis, SC: Saberes em Diálogo, 2015. p. 253-269.

LENZA, Pedro. Direito Constitucional Esquematizado. 24. ed. São Paulo: Saraiva 2020.

LOUREIRO, Antonio José Cacheado; RODRIGUES, Gustavo Henrique Soares. A

Religião na Constituição Imperial do Brasil: Análise Jurídico-Positiva Das Referências Religiosas na Carta Política de 1824. Disponível em: https://ambitojuridico.com.br/ cadernos/direito-constitucional/a-religiao-na-constituicao-imperial-do-brasil-analisejuridico-positiva-das-referencias-religiosas-na-carta-politica-de-1824/. Acesso em: 11 mar. 2020.

MENDES, Gilmar Ferreira; BRANCO, Paulo Gustavo Gonet. Curso de Direito Constitucional. (Rev. e atual.). 12. ed. São Paulo: Saraiva, 2017.

SANTOS, Tália de Azevedo Souto. Laicidade do Estado e Ensino Religioso no Brasil: trajetórias, desafios e perspectivas. 2019. 126 f. il. Dissertação (Mestrado em direitos humanos, cidadania e políticas públicas) - Universidade Federal da Paraíba, João Pessoa, 2019.

SARLET, Ingo Wolfigang. A Eficácia dos Direitos Fundamentais. Porto Alegre: Livraria do Advogado, 2018.

Submetido em: 9-4-2020

Aceito em: 21-5-2021 